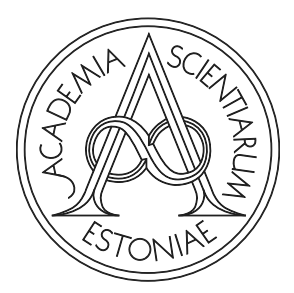

Proceedings of the Estonian Academy of Sciences, $2021, \mathbf{7 0}, 4 \mathrm{~S}, 354-360$

https://doi.org/10.3176/proc.2021.4S.07

Available online at www.eap.ee/proceedings

FORENSIC SCIENCE

\title{
The effect of various focal length photographs on eyewitness identification accuracy
}

\author{
Kristjan Kask*, Erlend Art Arras and Elina Malleus
}

Centre of Excellence in Behavioural and Neural Sciences, School of Natural Sciences and Health, Tallinn University, Narva mnt 25, 10120 Tallinn, Estonia

Received 17 October 2020, accepted 19 March 2021, available online 4 October 2021

(C) 2021 Authors. This is an Open Access article distributed under the terms and conditions of the Creative Commons AttributionNonCommercial 4.0 International License (http://creativecommons.org/licenses/by-nc/4.0/).

\begin{abstract}
A key factor that has rarely been investigated regarding the technical details of photographs in eyewitness identification research is focal length. Focal length can be defined as the distance between the camera lens and the camera sensor, providing variance in the viewing angle and magnification of objects in the frame. In this paper, the effect of various focal length photographs on eyewitness identification accuracy is examined. Ninety adult participants watched a video of a mock theft, after which they were randomly shown a simultaneous six-person target-present lineup of photographs using a $24 \mathrm{~mm}, 50 \mathrm{~mm}$ or $100 \mathrm{~mm}$ focal length. The participants who viewed photographs taken with either a $100 \mathrm{~mm}$ or $50 \mathrm{~mm}$ focal length identified the suspect more often than those who viewed photographs taken with a $24 \mathrm{~mm}$ focal length. Based on these findings, we suggest that the standard focal length of photographs used for the purpose of eyewitness identification should always be between $50 \mathrm{~mm}$ and $100 \mathrm{~mm}$.
\end{abstract}

Key words: focal length, eyewitness identification, simultaneous lineup, confidence, accuracy.

\section{INTRODUCTION}

Our ability to recognise human faces has been studied extensively in several contexts (e.g., Lindsay et al. 2007; Tistarelli et al. 2009; Hole and Bourne 2010; Lampinen et al. 2012; Wilkinson and Rynn 2012; Fitzgerald et al. 2018). In eyewitness identification studies, portrait photographs (mostly passport style photos) are often used as stimuli (Lindsay et al. 2007; Lampinen et al. 2012). However, we should bear in mind that several factors have an effect on how portrait photography reflects reality (Třebický et al. 2016), such as exposure (e.g., under- or overexposure of images and the inappropriate use of ISO, shutter speed, and aperture combinations), depth of field (e.g., the parameter related to focal length and aperture of the lens as well as to focusing distance from the subject), optical aberrations of the lenses used (e.g., radial and perspective distortions), colour representations and light-

\footnotetext{
${ }^{*}$ Corresponding author, kristjan.kask@tlu.ee
}

ing setup (e.g., the number and type of lights and light modifier used), but also spatial frequency, i.e., finegrained details (depending on the camera performance, the focal length used, and the shot distance) (see also Lampinen et al. 2014). These specifics may be difficult to control when photographing real-life situations.

Třebický et al. (2016) point out that detailed descriptions of photograph acquisition and standardization, such as focal length, are often missing, which may influence the assessment of validity and accurate replication of previous findings. Focal length can be defined as the distance between the camera lens and camera sensor providing variance in the viewing angle and magnification of objects in the frame (from wide angle fish-eye lenses to narrow telephoto lenses). Moreover, the use of different focal distances may have an effect on objects in the picture, resulting in different degrees of distortion. Třebický et al. (2016) note that the most common types of distortion in photography are radial distortions, where straight lines are rendered as curved lines (i.e., barrel and 
pincushion distortion), and perspective distortions, which are determined by the viewpoint from which the photograph is taken in relation to the target (i.e., nearby elements are rendered larger than distant ones). Due to these distortions, artefacts in size and shape representations may occur in photographs.

Focal length is related to the camera's sensor size; cameras with cropped (i.e., smaller) sensors with different crop factors result in narrower angles compared to traditional 35mm lenses (Langford 1998). For example, most DSLR cameras have crop factors of 1.5 to 1.6, while smartphone cameras use factors of around 6. This means that when taking a photograph of a subject (person/object) from the same distance, it appears closer when using cameras with cropped sensors (e.g., by using a camera with a crop factor of 1.6 and a $50 \mathrm{~mm}$ lens designed for full-frame cameras, it appears as a $80 \mathrm{~mm}$ camera lens in front of a cropped sensor camera). This should be taken into account and duly documented. Certain studies have reported in detail the procedure for photograph acquisition (Verhoff et al. 2008; Peron et al. 2012; Třebický et al. 2016). However, the methodology used appears to vary across individual studies.

In eyewitness identification research, in both field and laboratory settings, lineups can be presented to the witnesses either live, in videos, or via still photographs (Fitzgerald et al. 2018). If presented by using photographs, the quality of photographs has been studied previously (for example, see Bindemann et al. 2013; Schyns et al. 2002; Sinha et al. 2006; Knoche et al. 2005). However, as Třebický et al. (2016) stated, detailed descriptions of photographic acquisition, such as focal length, are often missing.

Similarly to the aforesaid research, the Code of Criminal Procedure of the Republic of Estonia does not, for example, mention or detail how photographs for lineups should be taken. However, concerning the quality of document photographs, there are strict requirements. In Estonia, the technical requirements for photographs when applied to the issuance of identity documents (Subsection 4 of Section 4) state that the photograph must not be taken with a short focal length as it creates radial distortion of the face (Regulation of the Minister of Internal Affairs 2016). However, there are no details regarding any recommendations as to what a "short focal length" is deemed to be. In countries such as Finland, Germany, and Australia, a focal length of $90-130 \mathrm{~mm}$ is deemed sufficient ( $35 \mathrm{~mm}$ film equivalent focal length) for the photographic image to be taken at a sufficient distance (Police of Finland 2019; Germany Visa 2021; Australian Government 2018). In the United States of America, the entire face must be in focus, with an approximate focal length of $105 \mathrm{~mm}$ (U. S. Department of State 2021).
Banks et al. (2014) noted that photographers have a rule of thumb that a $50 \mathrm{~mm}$ focal length produces naturallooking photos as the angle of view is similar to that of the human eye. Also, faces appear narrower when photographed with a shorter focal length and wider when photographed with a longer focal length. In addition, a longer focal length can make a person look more intelligent and attractive (Perona 2007) whereas a shorter lens has the opposite effect.

The $85 \mathrm{~mm}$ and $105 \mathrm{~mm}$ focal lengths (for $35 \mathrm{~mm}$ fullframe sensor) are most frequently used in portrait photography (Kelby 2010) and do not exceed ordinary space requirements between the target and the camera, concurrently providing the same field of view. Moreover, lenses producing $50 \mathrm{~mm}$ focal lengths are frequently used as standard or prime lenses, as they are believed to be equivalent in focal length to the human eye and are adept at creating natural-looking images (Jenkins and White 2001). Wide-angle fixed focal length lenses may not often be used separately, but there is a variety of zoom lenses which have a wide-angle possibility that may be used impromptu in narrower rooms. In addition, most smartphone cameras have wide-angle lenses, and there may be situations where smartphones are used instead of handheld cameras to make such photographs. Therefore, it is important to understand how wider focal distances affect recognition, as well as other more often used focal distances. To our knowledge, it appears that there is no solid evidence supporting this notion in specific eyewitness related studies ( Třebický et al. 2016).

In addition to accuracy, it is also important to examine the confidence of suspect identifications by eyewitnesses. It is known from previous research that the accuracy of suspect identifications and witness confidence are strongly associated, if confidence is recorded immediately after the suspect identification and the lineup was conducted according to recommendations (see Wixted and Wells 2017). If the lineup is conducted fairly, then witness confidence is detected to be a highly reliable indicator of accuracy (Wixted et al. 2016).

In this exploratory study, we examined the effect of different focal length photographs $(24 \mathrm{~mm}, 50 \mathrm{~mm}$, and $100 \mathrm{~mm}$ ) on eyewitness identification accuracy in simultaneous target-present lineups (i.e., photos of the suspect and persons similar to the suspect presented together). It is known that a $50 \mathrm{~mm}$ focal length is often used to take photographs of faces because this focal length is believed to be most similar to the focal length of the human eye (Jenkins and White 2001; see also Banks et al. 2014); however, in practice (Police of Finland 2019; Germany Visa 2021; Australian Government 2018; U. S. Department of State 2021) a focal length of $90-130 \mathrm{~mm}$ is used. Therefore, we hypothesize that suspect identifications will be more accurate with photographs taken with a $50 \mathrm{~mm}$ or 
$100 \mathrm{~mm}$ focal length compared to $24 \mathrm{~mm}$ focal length photographs. In addition, we hypothesize that accurate witnesses will be more confident in their identification decision.

\section{METHODS AND MATERIALS}

\section{Sample}

The sample consisted of 90 participants (32 males, 57 females, 1 unspecified) with a mean age of 24.3 years $(S D=5.18$, range 18-47). All participants had normal or corrected to normal visual acuity. Of these participants, 1 (1\%) had basic, 55 (63\%) secondary, 14 (15\%) vocational, and 19 (21\%) higher education. The participants' native language was Estonian in $82(92 \%)$ of the cases; in seven cases the native language was Russian or other (8\%). All participants had sufficient knowledge to communicate in Estonian in order to participate in this research. The experiment was conducted in accordance with the Declaration of Helsinki.

\section{Materials}

Stimulus video. For the experiment, a stimulus video of a theft was filmed using a digital single-lens reflex camera (Canon EOS 70D lens Canon EF-S 18-135mm f/3.5-5.6 IS STM) in which one young adult male (the suspect) stole the mobile telephone of a similar-aged female (the victim). The video was filmed from an eyewitness perspective (distance 4 meters) using only existing room lighting, and the total time of the event lasted about 22 seconds. The face of the suspect was visible both in full frontal but also from different angles from left or right. The specifications of the video footage were as follows: frame size $1920 \times 1080,24$ frames per second, shutter speed $1 / 50$.
Construction of the lineups. Two persons were invited to view the suspect photographs separately for about 10 seconds per image. Both persons described the suspect as "a male in his 20s, with short dark hair, narrow face, medium-size lips and narrow eyebrows". Full frontal head and shoulder colour photographs $(24 \mathrm{~mm}, 50 \mathrm{~mm}$, and $100 \mathrm{~mm}$ focal lengths using APS-C camera and compatible EF-S lens) of the suspect and nine other persons (similar to the suspect) were taken with the same camera that filmed the stimulus video (see Fig. 1). The photographer's distance from the subject varied when applying different focal lengths (e.g., the photographer stood closer when operating with a $24 \mathrm{~mm}$ focal length). The same shutter speed (1/160), aperture (f8), and ISO (100) were used in all the pictures. The images were saved in a .jpg format and were not edited or cropped afterwards in postproduction (contrast $M=135.09, S D=5.53$; luminosity $M=135.79, S D=5.55$ ). The lighting setup with the help of three strobes is shown in Fig. 2. This lighting rig was constructed in order to achieve a flat-light setup similar to the setup often used in standard passport photography.

A set of 10 photographs (50mm focal length) was presented to a group of mock witnesses $(n=21$, mean age 23 years, 9 males, 12 females) who had previously read the description of the suspect and subsequently chose photographs that corresponded most closely to the written description. The suspect was selected by six of the mock witnesses. In constructing the lineups, we applied the procedure suggested by Malpass and Lindsay (1999). The critical difference of choosing the suspect more often than chance was 1.77 (a lineup is biased when the coefficient is larger than 1.96, $p<0.05$; see Malpass and Lindsay 1999). Then lineup fairness (Tredoux’s E) (Tredoux 1998) was calculated: $\mathrm{E}=5.33$, range $4.01-7.95, p<0.05$ (Malpass and Lindsay 1999). Therefore, we concluded that a six-person lineup is sufficient.

The photographs were also shown to another group of 41 mock witnesses (average age 21, 11 males, 30 females)

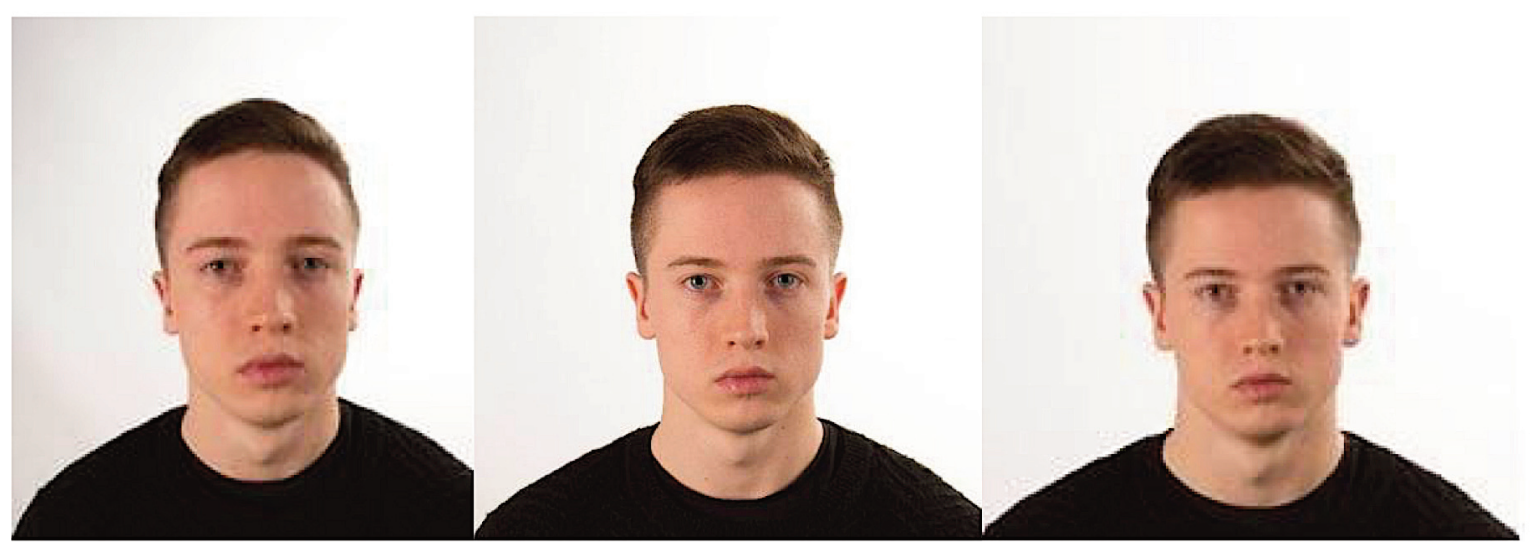

Fig. 1. $24 \mathrm{~mm}, 50 \mathrm{~mm}$, and $100 \mathrm{~mm}$ focal length photos of the suspect. 


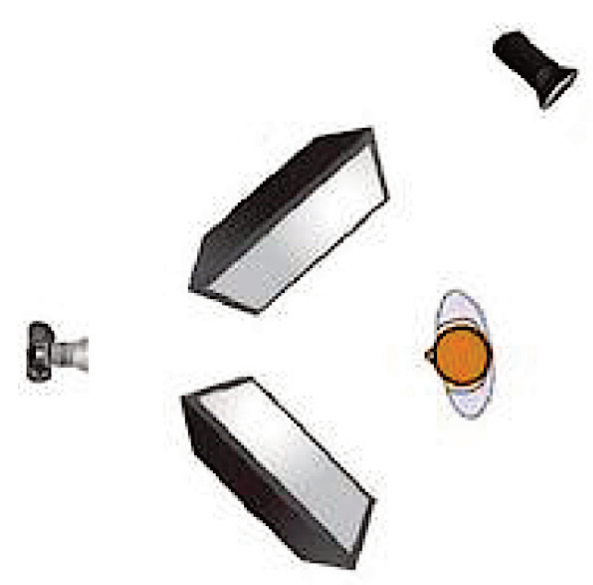

Fig. 2. Lighting setup.

who were asked to choose a face that was distinguishable for them, according to the Doob and Kirshenbaum (1973) procedure, and to evaluate the similarity of the photographs to the suspect on a 5-point Likert scale $(1=$ not similar at all; 5 = very similar). Two photographs were removed as they were selected more often than expected by chance. The next five persons, based on the similarity rating, were used as foils to form the six-person lineup used in the study.

Eighteen different versions of six-person lineups were constructed (six with $24 \mathrm{~mm}$, six with $50 \mathrm{~mm}$, and six with $100 \mathrm{~mm}$ focal length) where the spatial positions of the suspect and foils were randomly changed. The lineups were presented to the witnesses using a Microsoft PowerPoint 2013 slide show. The photographs $(6.44 \times$ $8.5 \mathrm{~cm})$ in the simultaneous lineup were presented in two rows (three photos in each row).

\section{Procedure}

The participants were tested individually. First the participant completed a consent form to participate in the experiment. Then the participant watched a video of a theft episode using a 23" monitor ("Please watch the following video clip').

Then the participants' visual acuity was tested by means of the Freiburg Visual Acuity and Contrast Test (FrACT) software version 3.9.3 (Bach 2007) where 18 trials of Landolt $\mathrm{Cs}$ are presented to measure visual acuity (a score of 1.0 or above corresponds to 'normal' visual acuity). The participants were also asked which type of visual acuity aids they use (eyeglasses, lenses, or whether they have had laser eye surgery to correct their vision).

Subsequently two distractor tasks were conducted to create temporal distance between watching the stimulus video and viewing the lineup. The first distractor task was the Stroop Colour and Word Test (Stroop 1935) using a computer program PsychoPy (Peirce 2007). After that another distractor task, a dichotic listening test, was applied (based on the standard Bergen Dichotic Listening paradigm, Hugdahl 2000) using E-Prime 2.0 software (Psychology Software Tools, Inc. 2020). Auditory stimuli were presented through headphones Sennheiser HD202.

Finally, the suspect identification phase took place. The participants were randomly shown one simultaneous six-person target-present lineup with photographs taken with either $24 \mathrm{~mm}(n=29), 50 \mathrm{~mm}(n=30)$, or $100 \mathrm{~mm}$ $(n=30)$ focal length. The participants were told that the person who stole the mobile phone may or may not be among the photos. "In a moment I will show you a lineup consisting of photographs, and the person you saw in the videoclip may or may not be among the photographs in the lineup. Look at the photographs as long as you wish." The positions of the suspect and foils were randomly changed in the lineups. After viewing a lineup, the participant was asked to make his or her decision ('Please state in which position, if any, the person you saw in the videoclip was in this lineup') and to give a confidence rating of their decision on a 10-point Likert scale (1 - not sure at all; 10 - sure; see Sauer and Brewer 2015).

\section{Statistical analysis}

In all conditions (focal length of $24 \mathrm{~mm}, 50 \mathrm{~mm}$, or $100 \mathrm{~mm}$ ) there were 29-30 participants per cell, which is consistent with the norm within the eyewitness identification literature of approximately 20 participants per group (Wilcock et al. 2018). A post hoc power analysis on the sample of 90 was conducted by means of the software package GPower (Faul et al. 2009). The recommended effect sizes used for this analysis were as follows: small $(\mathrm{w}=.10)$, medium $(\mathrm{w}=.25)$, and large $(\mathrm{w}=.40$; see Cohen 1988). The alpha level used for this analysis was $p<.05$. Post hoc analyses indicated that the statistical power for this study was .12 for detecting a small effect, .64 for detecting a medium effect, and .97 for detecting a large effect. In sum, there was adequate power to detect a large effect but less than adequate statistical power to detect a small or medium effect. For all tests, $p$-values $<$ .05 (one-tailed) were considered statistically significant. All analyses were performed using IBM SPSS software version 27. 


\section{RESULTS}

The three groups of participants (who observed the photographs taken with either $24 \mathrm{~mm}, 50 \mathrm{~mm}$, or $100 \mathrm{~mm}$ focal length) did not differ significantly in terms of gender, $\chi^{2}(2)=.145, p=.930$, Cramer's $\mathrm{V}=.04$, or age, $F<2$, $p>.20, \eta^{2}=.04$. Forty-seven (52.8\%) participants needed no correction for visual acuity, $22(24.7 \%)$ wore glasses, $16(17.9 \%)$ wore corrective lenses, and four (4.6\%) had had corrective laser eye surgery. A one-way ANOVA indicated significant differences in visual acuity scores $F(3,89)=3.29, p=.025, \eta^{2}=.104,1-\beta=.733$; however, Scheffé post-hoc analysis revealed no differences among the groups (without any correction $M=1.49, S D=.14$; glasses $M=1.39, S D=.22$; lenses $M=1.36, S D=.16$; laser eye surgery $M=1.45, S D=.21)$. There were no differences in visual acuity scores among the three condition groups $(F<1, p>.80)$.

A chi-square analysis applying Fisher's Exact method indicated a statistically significant difference among the three focal length groups (see Table 1$), \chi^{2}(4)=15.68$, $p=.003$, Cramer's V $=.297$. More specifically, the participants who viewed photographs taken with a $100 \mathrm{~mm}$ focal length correctly identified the suspect more often than the participants who viewed photographs taken with a $24 \mathrm{~mm}$ focal length, $\chi^{2}(2)=12.67, p=.002$, Cramer's $\mathrm{V}=.463$. Similarly, the participants who viewed photographs taken with a $50 \mathrm{~mm}$ focal length correctly identified the suspect more often than the participants who viewed photographs taken with a $24 \mathrm{~mm}$ focal length, $\chi^{2}(2)=7.33, p=.026$, Cramer's $\mathrm{V}=.35$. There was no difference in identification accuracy between the participants who viewed photographs taken with a $50 \mathrm{~mm}$ or $100 \mathrm{~mm}$ focal length, $\chi^{2}(2)=2.32, p=.31$, Cramer's $V=.197$.

The effect of focal length and identification accuracy on confidence ratings was further analysed using a twoway 3 (focal length: $24 \mathrm{~mm}, 50 \mathrm{~mm}$, or $100 \mathrm{~mm}$ ) $\times 3$ (accuracy: correct identification, foil identification, or incorrect rejection) ANOVA. There was a significant effect of identification accuracy, $F(2,89)=5.35, p=.01$, $\eta^{2}=.118,1-\beta=.827\left(r_{\mathrm{s}}=.251, p<.01\right)$. Scheffé posthoc tests indicate that confidence ratings for correct identifications $(M=7.32, S D=1.96)$ and incorrect rejections $(M=7.30, S D=2.10)$ were higher than for foil

Table 1. Identification decisions as a function of different focal lengths

\begin{tabular}{lcc|c}
\hline \multicolumn{1}{c|}{ Decision } & $24 \mathrm{~mm}$ & $50 \mathrm{~mm}$ & $100 \mathrm{~mm}$ \\
\hline Accurate identification & $9(31 \%)$ & $18(60 \%)$ & $23(77 \%)$ \\
Foil identification & $6(21 \%)$ & $7(23 \%)$ & $3(10 \%)$ \\
Incorrect rejection & $14(48 \%)$ & $5(17 \%)$ & $4(13 \%)$
\end{tabular}

identifications $(M=5.31, S D=1.45)(p<.01)$. However, there was no significant effect of focal length $(F<1$, $p>.35)$ and no significant interaction between focal length and accuracy $(F<2, p>.10)$.

\section{DISCUSSION}

In this study, we examined the effect of photographs taken with different focal lengths on eyewitness identification accuracy and confidence ratings of identification decisions. We detected that the focal length of a lens had an effect on accuracy. The photographs taken by using a $24 \mathrm{~mm}$ focal length were correctly identified less often than the photographs taken with a $50 \mathrm{~mm}$ or $100 \mathrm{~mm}$ focal length.

This is a novel finding in the context of eyewitness identification research. Wide-angle lenses may be used in real-life situations (narrow room conditions, smartphone photography), but previous face recognition studies have only reported focal lengths of $50 \mathrm{~mm}$ and above ( Třebický et al. 2016). Current findings suggest that using a wider angle when taking photographs may distort persons' faces by making facial features closer to the camera (nose, eyes) appear larger than those farther away (ears). Wider angles are often used in smartphone camera lenses, which may not be the best option for photographing criminal suspects. In contrast, using a telephoto lens may widen a face by making it appear less dimensional. In this study, suspect photographs taken with a $50 \mathrm{~mm}$ or $100 \mathrm{~mm}$ focal length were correctly identified by witnesses at the same rate. A $100 \mathrm{~mm}$ focal distance can be described as a telephoto distance, but it may not distort the face shape sufficiently to affect the accuracy of face identification. Narrower angles may have a larger effect on the perception of face shapes. In addition to focal length, other parameters may also influence identification accuracy of photographs, for example, different lighting conditions.

Confidence ratings for accurate identifications were higher regardless of the focal length of the photographs, which corresponds to previous findings (Wixted and Wells 2017). However, it would be worthwhile to further examine why there were no differences between photographs of different focal lengths.

Although identification accuracy using photographs taken with a $100 \mathrm{~mm}$ focal length did not differ from photographs taken with a $50 \mathrm{~mm}$ focal length, the participants who viewed $100 \mathrm{~mm}$ photographs (compared to $24 \mathrm{~mm}$ or $50 \mathrm{~mm}$ photographs) were two times less likely to identify an innocent filler in the lineup (which is considered a grave error in target-present lineups, Mickes and Gronlund 2017). In other words, 100mm photographs may produce fewer errors. We are constrained in the conclusions that can be drawn from our exploratory study 
because our sample size was small and we used only one target and persons similar to that target. To overcome these limitations, the experiment should be replicated with a larger sample size (to achieve higher power) and with different stimuli (at least two different mock crimes with two different suspects), involving also a target-absent lineup (where the correct decision would be to say that the suspect is not present). In that case, more precise information regarding the impact of different focal lengths on identification accuracy could be achieved.

\section{CONCLUSIONS}

It can be concluded that although different countries have different requirements for official photographs (i.e., passports), we recommend, similarly to previous research (Verhoff et al. 2008; Třebický et al. 2016), that the procedure for photographic acquisition (i.e., focal length) should be reported in detail in both eyewitness identification research and when constructing lineups in actual criminal cases. Based on these findings, we recommend that the photographic focal length for research and criminal investigative purposes should always be between $50 \mathrm{~mm}$ and $100 \mathrm{~m}$ using a $35 \mathrm{~mm}$ full-frame camera.

\section{ACKNOWLEDGEMENTS}

This research was supported by Tallinn University Research Fund Project TF1515 "The Centre of Excellence in Behavioural and Neural Science", Tallinn University ASTRA Project "TU TEE - Tallinn University as a promoter of intelligent lifestyle" financed by the European Union European Regional Development Fund 2014-2020.4.01.160033 . The publication costs of this article were covered by the Estonian Academy of Sciences.

\section{REFERENCES}

Australian Government. 2018. Camera Operator Guidelines. https://www.passports.gov.au/files/brochure-camera-operatorguidelines (accessed 2019-11-12).

Bach, M. 2007. The Freiburg Visual Acuity Test - Variability unchanged by post-hoc re-analysis. Graefes Arch. Clin. Exp. Ophthalmol., 245, 965-971. https://doi.org/10.1007/s00417006-0474-4

Banks, M. S., Cooper, E. A. and Piazza, E. A. 2014. Camera focal length and the perception of pictures. Ecol. Psychol., 26, 30-46. https://doi.org/10.1080/10407413.2014.877284

Bindemann, M., Attard, J., Leach, A. and Johnston, R. A. 2013. The effect of image pixelation on unfamiliar-face matching. Appl. Cogn. Psychol., 27(6), 707-717. https://doi.org/ 10.1002/ACP.2970
Cohen, J. 1988. Statistical Power Analysis for the Behavioural Sciences. 2nd edition. Lawrence Erlbaum Associates, Hillsdale, NJ.

Doob, A. N. and Kirshenbaum, H. M. 1973. The effects on arousal of frustration and aggressive films. J. Exp. Soc. Psychol., 9(1), 57-64.

Faul, F., Erdfelder, E., Buchner, A. and Lang, A.-G. 2009. Statistical power analyses using $\mathrm{G}^{*}$ Power 3.1: Tests for correlation and regression analyses. Behav. Res. Methods, 41, 1149-1160. https://doi.org/10.3758/ BRM.41.4.1149

Fitzgerald, R. J., Price, H. L. and Valentine, T. 2018. Eyewitness identification: Live, photo, and video lineups. Psychol. Public Policy, Law, 24(3), 307-325. https://doi.org/10.1037/ law0000164

Germany Visa. 2021. Visa Photo Requirements. https://www. germany-visa.org/visa-photo-requirements (accessed 202109-11).

Hole, G. and Bourne, V. 2010. Face Processing: Psychological, Neuropsychological and Applied Perspectives. Oxford University Press.

Hugdahl, K. 2000. What can be learned about brain function from dichotic listening? Rev. Esp. Neuropsicol., 2(3), 62-84.

Jenkins, F. A. and White, H. E. 2001. Fundamentals of Optics. 4th ed. McGraw-Hill, New York, NY.

Kelby, S. 2010. The Digital Photography Book, vol. 3. Peachpit Press, San Francisco, CA.

Knoche, H., McCarthy, J. D. and Sasse, M. A. 2005. Can small be beautiful? Assessing image resolution requirements for mobile TV. In MULTIMEDIA '05: Proceedings of the 13th Annual ACM International Conference on Multimedia, Singapore, November 6-11, 2005, 829-838.

Lampinen, J. M., Neuschatz, J. S. and Cling, A. D. 2012. The Psychology of Eyewitness Identification (Essays in Cognitive Psychology). Psychology Press, New York, NY.

Lampinen, J. M., Erickson, W. B., Moore, K. N. and Hittson, A. 2014. Effects of distance on face recognition: implications for eyewitness identification. Psychonomic Bulletin \& Review, 21, 1489-1494. https://doi.org/10.3758/s13423014-0641-2

Langford, M. 1998. Advanced Photography. Focal Press, Oxford.

Lindsay, R. C. L., Ross, D. F., Read, J. D. and Toglia, M. P. (eds). 2007. The Handbook of Eyewitness Psychology: Memory for People, vol. 2. Psychology Press, New York, NY.

Malpass, R. S. and Lindsay, R. C. L. 1999. Measuring lineup fairness. Appl. Cogn. Psychol., 13(S1), S1-S7. https://doi.org/ 10.1002/(SICI)1099-0720(199911)13:1+<S1::AID-ACP678 $>3.0 . \mathrm{CO} ; 2-9$

Mickes, L. and Gronlund, S. D. 2017. Eyewitness identification. In Learning and Memory: A Comprehensive Reference. 2nd ed. (Byrne, J. H., ed.), pp. 529-552, Elsevier.

Peirce, J. W. 2007. PsychoPy - Psychophysics software in Python. J. Neurosci. Methods, 162(1-2), 8-13. https://doi.org/ 10.1016/j.jneumeth.2006.11.017

Peron, A. P. L. M., Morosini, I. C., Correia, K. R., Moresca, R. and Petrelli, E. 2012. Photometric study of divine proportion and its correlation with facial attractiveness. Dental Press $J$. Orthod., 17(2), 124-131. https://doi.org/10.1590/S217694512012000200022

Perona, P. 2007. A new perspective on portraiture. J. Vis., 7, 992. https://doi.org/10.1167/7.9.992 
Police of Finland. 2019. Photography Technical Properties. https://www.poliisi.fi/licences/passport/photography_techni cal_properties (accessed 2019-11-12).

Psychology Software Tools, Inc. [E-Prime 2.0]. 2020. http://www.pstnet.com

Regulation of the Minister of Internal Affairs. 2016. Requirements for photographs in applying for issue of identity documents. State Gazette I, 18.11.2016, 5 (in Estonian).

Sauer, J. and Brewer, N. 2015. Confidence and accuracy of eyewitness identification. In Forensic Facial Identification: Theory and Practice of Identification from Eyewitnesses, Composites and CCTV (Valentine, T. and Davis, J. P., eds), pp. 185-208, Wiley Blackwell, Chichester.

Schyns, P. G., Bonnar, L. and Gosselin, F. 2002. Show me the features! Understanding recognition from the use of visual information. Psychol. Sci., 13(5), 402-409. https://doi.org/ 10.1111/1467-9280.00472

Sinha, P., Balas, B., Ostrovsky, Y. and Russell, R. 2006. Face recognition by humans: Nineteen results all computer vision researchers should know about. Proc. IEEE, 94(11), 19481962.

Stroop, J. R. 1935. Studies of interference in serial verbal reactions. J. Exp. Psychol., 18, 643-662.

Tistarelli, M., Li, S. Z. and Chellappa, R. (eds). 2009. Handbook of Remote Biometrics: for Surveillance and Security (Advances in Computer Vision and Pattern Recognition). Springer, London.

Tredoux, C. G. 1998. Statistical inference on measures of lineup fairness. Law Hum. Behav., 22(2), 217-237.
Třebický, V., Fialová, J., Kleisner, K. and Havlíček, J. 2016. Focal length affects depicted shape and perception of facial images. PloS One, 11(2), e0149313. https://doi.org/ 10.1371/journal.pone.0149313

U. S. Department of State. 2021. Guidelines for Producing High Quality Photographs for U.S. Travel Documents - for Visa Online Applications. https://dokument.pub/q1/guidelinesfor-producing-high-quality-photographs-for-us-flipbook-pdf (accessed 2021-09-12).

Verhoff, M. A., Witzel, C., Kreutz, K. and Ramsthaler, F. 2008. The ideal subject distance for passport pictures. Forensic Sci. Int., 178(2-3), 153-156. https://doi.org/10.1016/j.forsciint. 2008.03.011

Wilcock, R., Crane, L., Hobson, Z., Nash, G., Kirke-Smith, M. and Henry, L. A. 2018. Supporting child witnesses during identification lineups: Exploring the effectiveness of registered intermediaries. Appl. Cogn. Psychol., 32(3), 367375. https://doi.org/10.1002/acp.3412

Wilkinson, C. and Rynn, C. (eds). 2012. Craniofacial Identification. Cambridge University Press.

Wixted, J. T. and Wells, G. L. 2017. The relationship between eyewitness confidence and identification accuracy: A new synthesis. Psychol. Sci. Public Interest, 18(1), 10-65. https://doi.org/10.1177/1529100616686966

Wixted, J. T., Mickes, L., Dunn, J. C., Clark, S. E. and Wells, W. 2016. Estimating the reliability of eyewitness identifications from police lineups. Proc. Natl. Acad. Sci. U. S. A., 113(2), 304-309. https://doi.org/10.1073/pnas.1516814112

\section{Erineva fookuskaugusega pildistatud fotode mõju inimeste tuvastamise täpsusele}

\section{Kristjan Kask, Erlend Art Arras ja Elina Malleus}

Pealtnägijatunnistusi käsitlevates uurimustes on senini vähe analüüsitud tunnistajatele esitatavate fotode kvaliteediga seonduvaid faktoreid, näiteks fookuskaugust. Seda saab defineerida kui vahemaad fotograafilise läätse ja kaamera sensori vahel, kus varieeruvad nägemisnurk ning objektide suurendatavuse aste. Artiklis on uuritud erineva fookuskaugusega pildistatud fotode mõju inimeste tuvastamise täpsusele. 90 katseisikut vaatasid videot simuleeritud varguse episoodist, mis oli toime pandud ühe isiku poolt, ja pidid ta hiljem kuueliikmelisest samaaegsest äratundmiseks esitamise reast tuvastama. Reas esitatavad fotod olid pildistatud kas 24-, 50- või 100-mm fookuskaugusega. Need katseisikud, kes tuvastasid nähtud isikud 100- või 50-mm fookuskaugusega pildistatud fotode reas, olid täpsemad, võrreldes nendega, kes nägid 24-mm fookuskaugusega pildistatud fotode rida. Tulemustest lähtuvalt võib soovitada, et äratundmiseks esitamisel võiksid fotod olla pildistatud fookuskaugusega vahemikus 50-100 mm. 